\title{
Motor Cortex Is Functionally Organized as a Set of Spatially Distinct Representations for Complex Movements
}

\author{
Andrew R. Brown ${ }^{1,2}$ and G. Campbell Teskey ${ }^{1,2,3,4,5}$ \\ ${ }^{1}$ Hotchkiss Brain Institute, Departments of ${ }^{2}$ Neuroscience, ${ }^{3}$ Cell Biology and Anatomy, ${ }^{4}$ Psychology, and ${ }^{5}$ Physiology and Pharmacology, University of \\ Calgary, Calgary, Alberta T2N 4N1, Canada
}

\begin{abstract}
There is a long-standing debate regarding the functional organization of motor cortex. Intracortical microstimulation (ICMS) studies have provided two contrasting views depending on the duration of stimulation. In the rat, short-duration ICMS reveals two spatially distributed forelimb movement representations, the rostral forelimb area (RFA) and caudal forelimb area (CFA), eliciting identical movements. In contrast, long-duration ICMS reveals spatially distributed, complex, multijoint movement areas, with grasping found exclusively in the rostral area and reach-shaping movements of the arm located in the caudal area. To provide corroboration for which interpretation is correct, we selectively inactivated the RFA/grasp area during the performance of skilled forelimb behaviors using a reversible cortical cooling deactivation technique. A significant impairment of grasping in the single-pellet retrieval task and manipulations of pasta was observed during cooling deactivation of the RFA/grasp area, but not the CFA/arm area. Our results indicate a movement-based, rather than a muscle-based, functional organization of motor cortex, and provide evidence for a conserved homology of independent grasp and reach circuitry shared between primates and rats.
\end{abstract}

Key words: behavior; intracortical microstimulation; rat; reversible lesion

\section{Introduction}

The role of the motor cortex has long been investigated with electrical stimulation (Fritsche and Hitzig, 1870; Ferrier, 1874), yet its intrinsic functional organization continues to be debated (Graziano et al., 2002; Harrison et al., 2012). Intracortical microstimulation using short-duration pulse trains [short-duration intracortical microstimulation (SD-ICMS); $<50 \mathrm{~ms}$ ] elicits brief muscle twitches revealing a somatotopic mapping of body musculature (muscle map) in primates (Penfield and Bouldrey, 1937; Woolsey et al., 1952; Asanuma and Rosén, 1972; Andersen et al., 1975; Donoghue et al., 1992; Yao et al., 2013) and rodents (Neafsey et al., 1986; Donoghue and Wise, 1982; Young et al., 2011; Tennant et al., 2012). Internal somatotopic organization within representations, however, is not readily observed; although representations of the forelimb can be delineated from the hindlimb, muscle representations within the forelimb area are intermixed. In addition, multiple and overlapping representations of the same body part have been found (Luppino et al., 1991; Schieber, 2001). Stimulation using long-duration pulse trains [longduration ICMS (LD-ICMS); 500 ms] on a behaviorally relevant

Received June 18, 2014; revised Aug. 12, 2014; accepted Aug. 23, 2014.

Author contributions: A.R.B. and G.C.T. designed research; A.R.B. performed research; A.R.B. analyzed data; A.R.B. and G.C.T. wrote the paper.

This work was supported by a Discovery grant from the Natural Sciences and Engineering Research Council of Canada (NSERC; to G.C.T.); in addition to NSERC, Alberta Innovates Health Solutions, and NSERC Silver Anniversary graduate studentships (A.R.B.).

The authors declare no competing financial interests.

Correspondence should be addressed to G. Campbell Teskey, Department of Cell Biology and Anatomy, University of Calgary, 3330 Hospital Drive, NW, Calgary, AB T2N 4N1, Canada. E-mail: gteskey@ucalgary.ca.

DOI:10.1523/JNEUROSCI.2500-14.2014

Copyright $\odot 2014$ the authors $\quad 0270-6474 / 14 / 3413574-12 \$ 15.00 / 0$ time scale has been shown to evoke complex coordinated movements of one or more body parts toward specific postures in primates (Graziano et al., 2002, 2005; Haiss and Schwarz, 2005; Gharbawie et al., 2011b; Overduin et al., 2012) and rats (Ramanathan et al., 2006; Harrison et al., 2012; Bonazzi et al., 2013). A variety of different movement classes can be elicited from different regions of cortex (movement map) that bear resemblance to the behavioral repertoire of the species (Graziano et al., 2002). These two stimulation paradigms implicate drastically different interpretations for the functional organization of motor cortex.

Forelimb movements evoked with SD-ICMS in the rat comprise twitches of distal (digits, wrist) and proximal (elbow, shoulder) musculature elicited from a smaller rostral forelimb area (RFA) and a larger caudal forelimb area (CFA). LD-ICMS evokes reach-to-grasp behavior in the rat, with grasping representations localized in the RFA, and forelimb elevation, advance, and retraction localized in the CFA (Ramanathan et al., 2006; Bonazzi et al., 2013). The segregation of these two motor areas provides an ideal opportunity in which to investigate distinct predictions that can be made on the functional organization of motor cortex. According to the muscle somatotopy hypothesis, deactivation of the RFA should not produce a specific deficit in forelimb motor ability relative to CFA deactivation as both regions contain a representation of forelimb musculature (SD-ICMS). On the other hand, if the motor cortex is organized as a map of complex movement representations (LD-ICMS), a deactivation of the grasping area (RFA) should result in specific forelimb grasping deficits.

We tested the hypothesis that reversible deactivation of the RFA, but not the CFA, would cause forelimb grasping deficits in behaving rats. Cortical cooling deactivation targeting the RFA/ grasp area, but not the CFA, was shown to elicit specific distal 
a

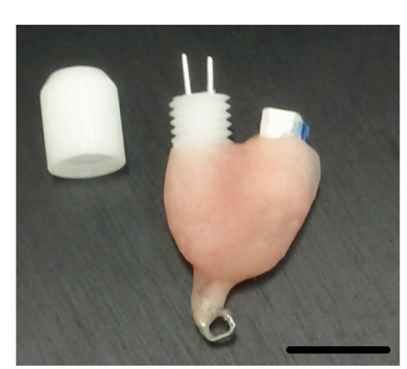

b

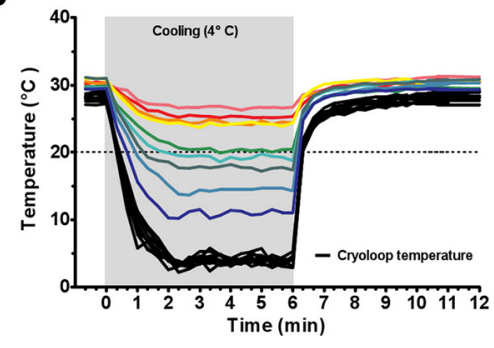

C

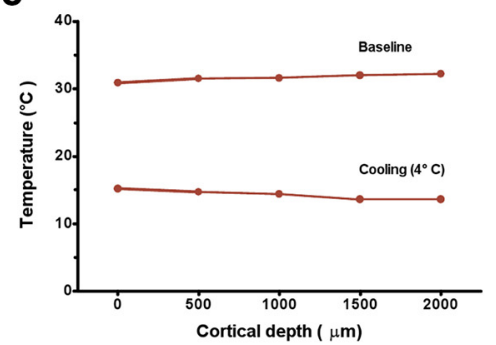

d

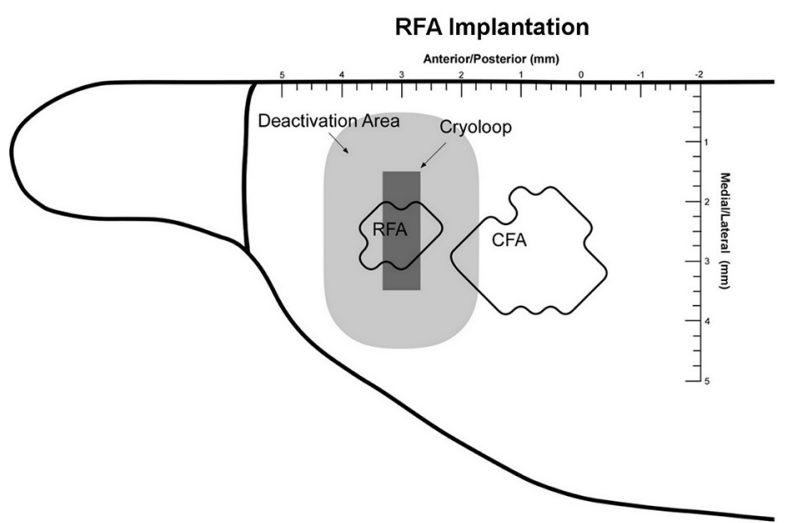

CFA Implantation

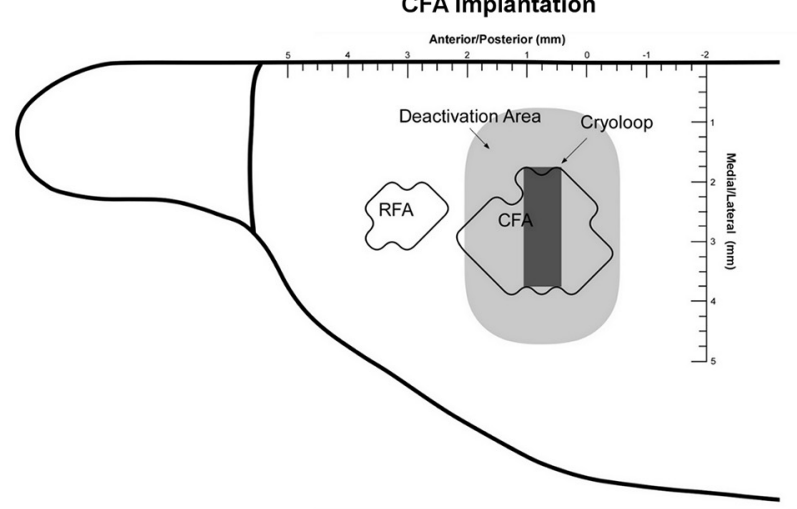

Figure 1. Time course and spread of cortical cooling. $\boldsymbol{a}$, Cortical cryoloop assembly. $\boldsymbol{b}$, Cortical temperature time course from cooling onset recorded $1500 \mu \mathrm{m}$ below the pial surface at varying distances from the cryoloop with a stable holding loop temperature of $4^{\circ} \mathrm{C}$. The threshold deactivation isotherm of $20^{\circ} \mathrm{C}$ (Lomber et al., 1999), below which synaptic block occurs, is plotted as a stippled line and is achieved within $1 \mathrm{~mm}$ of the cryoloop configuration used in this study. A rapid onset/offset of cortical inactivation can be achieved within $120 \mathrm{~s}$. c, Cortical depth temperature readings obtained from a penetration site $500 \mu \mathrm{m}$ away from the midpoint of the cryoloop with a holding loop temperature of $4^{\circ} \mathrm{C}$. Consistent temperatures were recorded across cortical laminae. $\boldsymbol{d}$, Schematic diagrams for cryoloop implantations and the extent of cortical deactivation (loop holding temperature, $4^{\circ} \mathrm{C}$ ) for RFA-cooled and CFA-cooled groups. Deactivation area is plotted to $1 \mathrm{~mm}$ away from the cryoloop using thermocline isotherm data in $\boldsymbol{b}$. Scale bar, $10 \mathrm{~mm}$.

grasping deficits in skilled reaching and vermicelli handling performance. Our results provide further corroborative evidence that complex movement representations relate to behavioral ability, and reveal a functionally distinct movement-based rather than muscle-based organization of motor cortex.

\section{Materials and Methods}

Rats. Thirty-nine male Long-Evans rats $(250-478 \mathrm{~g}$ at the time of electrophysiological mapping) were used in this experiment. Rats were obtained from Charles River and were housed individually in clear plastic cages in a colony room maintained on a $12 \mathrm{~h}$ light/dark cycle (lights on at 7:00 A.м.) at $21^{\circ} \mathrm{C}$. Upon arrival, rats were gently handled once per day (5 $\mathrm{min}$ ) for $5 \mathrm{~d}$ to minimize stress during behavioral testing. Experimentation was conducted between 8:00 A.M. and 11:00 P.M. Rats were provided free access to food and water (Prolab RMH 2500 lab diet, PMI Nutrition International) throughout the duration of their housing except for an overnight food restriction before electrophysiological mapping, and during behavioral training on the single-pellet reaching task. During reach training, rats were maintained to $90 \%$ free-feeding weight. All procedures involving rats used in this study strictly adhered to the guidelines of the Canadian Council on Animal Care and were approved by the Health Sciences Animal Care Committee of the University of Calgary. All efforts were made to adhere to the principles of reduction, refinement, and replacement in experimental design (Russell and Burch, 1959), with every attempt made to limit the number of subjects and minimize animal suffering.

Groups and experimental design. Rats were assigned to one of four experimental groups consisting of unimplanted untrained (naive; $n=$ 10), unimplanted reach-trained (reach-trained; $n=9$ ), CFA cryoloopimplanted reach-trained (CFA-cooled; $n=8$ ), and RFA cryoloopimplanted reach-trained (RFA-cooled; $n=9$ ) rats. Three additional rats were used to determine the time course and extent of cortical deactiva- tion as well as to verify the efficacy of the deactivation in abolishing evoked forelimb responses to ICMS. Unimplanted behaviorally naive rats were used to assess forelimb movement representation expression with LD-ICMS. Unimplanted reach-trained rats were used to assess reorganization of complex forelimb movement representations following 14 daily sessions of skilled reach training. Cryoloop-implanted groups were used to assess the behavioral impact of cooling deactivation in RFA-cooled and CFA-cooled groups. Implantation rats first underwent $14 \mathrm{~d}$ of pretraining in the single-pellet reaching task to determine hand preference and to establish baseline reaching performance. Cryoloops were then chronically implanted contralateral to the preferred reaching limb. Following 7-12 d of recovery, rats underwent ordered testing in a behavioral test battery of single-pellet reaching, vermicelli pasta handling, sunflower seed opening, and forelimb grip strength to assess limb motor function. Behavioral testing sessions consisted of three repeated cooling cycles under baseline (cooling off), cooling (cryoloop temperature maintained at $4^{\circ} \mathrm{C}$ ), and rewarm (cooling off) conditions. Each cycle was separated by 5 min intermissions to allow stable cortical temperatures to be reached. A single testing session was conducted per rat per day. Following behavioral testing, long-duration ICMS was used to confirm appropriate cryoloop placement and motor map integrity. Behavioral testing and ICMS sessions were video recorded (30 frames/s, 1/1000 s shutter) for off-line analysis.

Single-pellet training. Rats were placed on a restricted diet to maintain $90 \%$ of normal free-feeding body weight for the duration of training. Reach training was conducted in clear Plexiglas test boxes $45 \times 14 \times 35$ $\mathrm{cm}$. A $1 \mathrm{~cm}$ vertical aperture of Plexiglas was removed from the front wall, extending from $2 \mathrm{~cm}$ above the floor to a height of $15 \mathrm{~cm}$. A 4 -cm-wide shelf was fixed to the outside front wall $3 \mathrm{~cm}$ from the floor. The shelf contained two indentations $2 \mathrm{~cm}$ from the front wall and aligned with the edges of the aperture. 


\section{Complex movements}
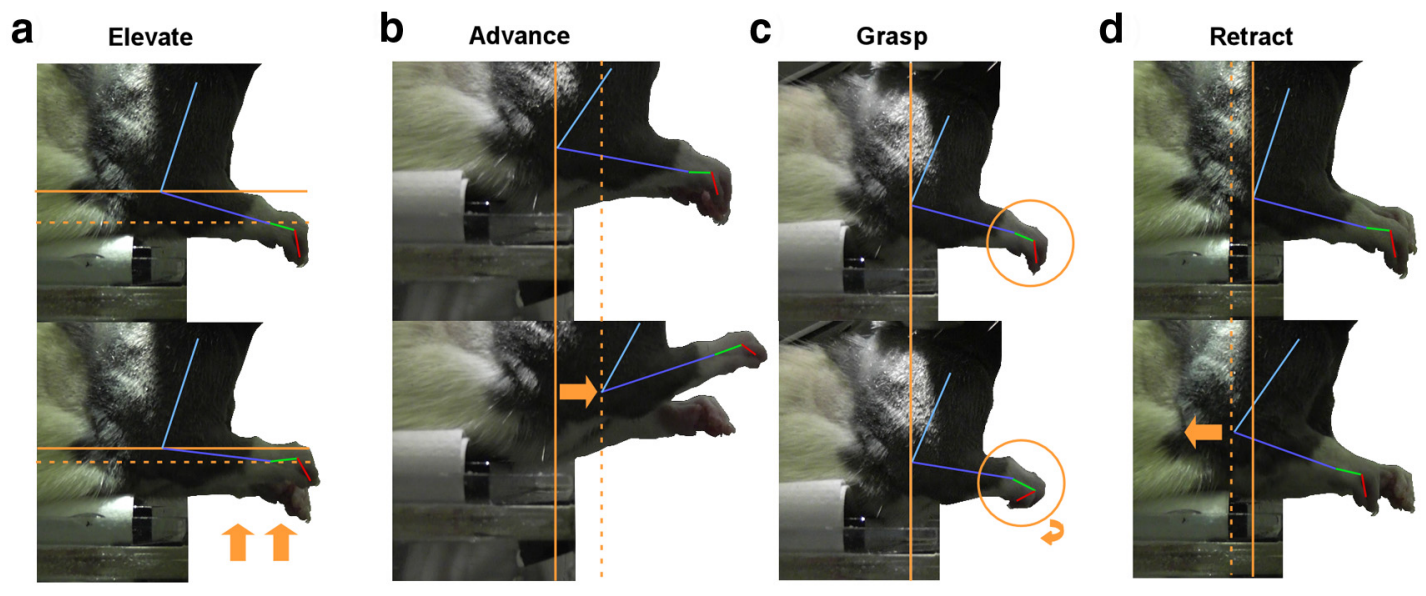

\section{Simple movements}
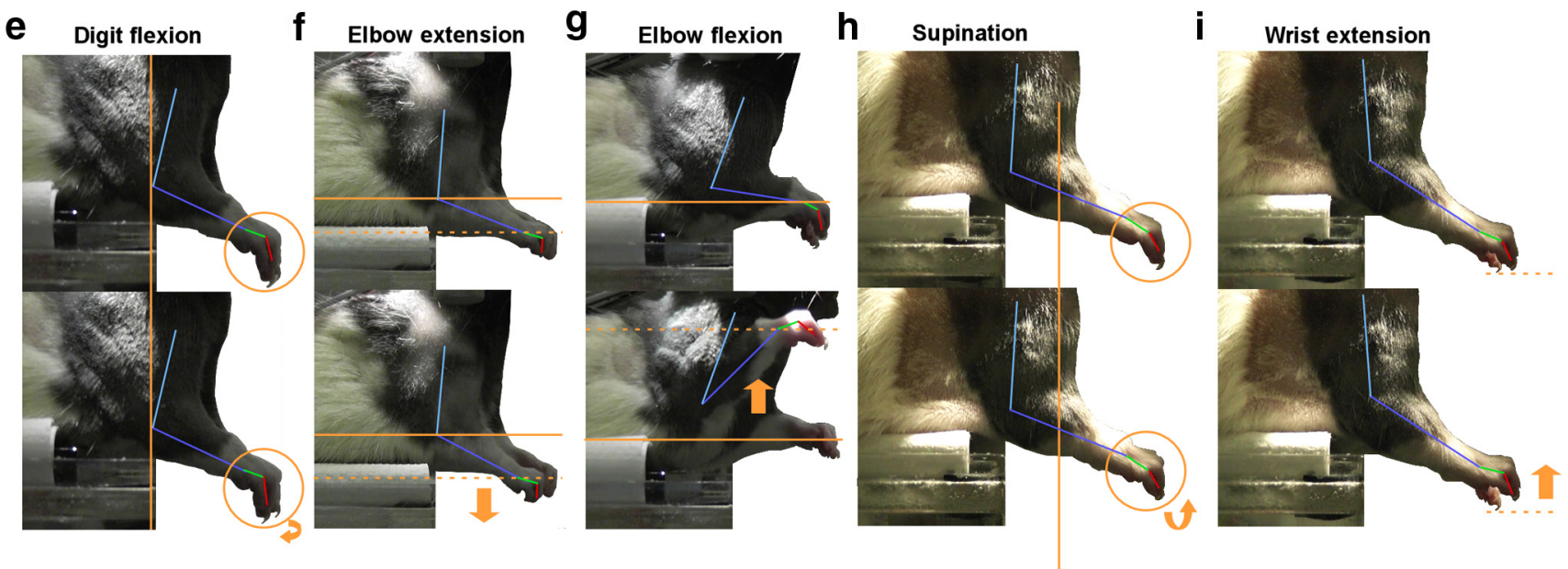

Figure 2. $\quad \boldsymbol{a}-\boldsymbol{i}$, Movement patterns elicited by long-duration intracortical microstimulation. Movements were classified as either simple, when involving a single forelimb joint, or complex, when involving multiple forelimb joints. Complex movements were classified as elevations involving flexion of the elbow followed by extension of the wrist (a), advances involving forward displacement of the elbow and shoulder with wrist extension and hand opening $(\boldsymbol{b})$, grasps involving flexion of the wrist and simultaneous digit contraction and hand closure (c), and retractions involving caudal displacement of the elbow and shoulder $(\boldsymbol{d})$. Simple movements consisted of flexions of the digits $(\boldsymbol{e})$ or elbow $(\boldsymbol{g})$, extensions of the elbow $(\boldsymbol{f})$ or wrist $(\boldsymbol{i})$, as well as supinations of the forelimb $(\boldsymbol{h})$.

During initial training, rats were placed in the apparatus for $10 \mathrm{~min}$ daily sessions where sucrose food pellets ( $45 \mathrm{mg}$; Bioserv Inc.) were placed in the shelf indentations to promote rat reaching through the front wall aperture and to determine hand preference. Hand preference was established when at least $60 \%$ of a minimum of 10 reach attempts were made using either the left or right forelimb. Following hand preference determination, daily training sessions were performed for a total of 14 sessions. Over the course of training, rats were shaped to reach with their preferred hand through the front wall aperture to successfully obtain a food pellet reward on the shelf. During each trial, the rat started at the rear of the test box and approached the front to reach through the aperture to obtain a pellet placed in the shelf indentation contralateral to the preferred hand. Only one reach attempt was permitted per trial. The reach was considered successful if the rat was able to successfully grasp the pellet from the shelf transfer it to the mouth without being dropped. Following each reach attempt, rats were shaped to return to the rear of the box for the next trial. During initial training sessions, rats were rewarded with a pellet placed in the back of the box after each trial to facilitate shaping. As training progressed, rats were rewarded only for successful reach attempts. Each session lasted $15 \mathrm{~min}$, during which time rats could perform as many trials as possible with the number of successful and unsuccessful reach attempts recorded. Performance in the task was measured using the percentage of success of reaching attempts, calculated as follows (Whishaw et al., 2003): [100 × (number of successful reaches) $/$ (number of total reaches)].

Cryoloop construction, implantation, and validation. Cryoloops were fashioned from 23 gauge $(0.635 \mathrm{~mm}$ outer diameter $\times 0.33 \mathrm{~mm}$ inner diameter) hypodermic stainless steel tubing. A linear $2 \mathrm{~mm}$ portion of the loop was shaped to conform to the surface of the cortical surface (Fig. 1a). A microthermocouple made from 30 gauge Teflon-insulated copper and Constantan wire was soldered to the union of the inlet and outlet tubes, which were led through a plastic, outside-threaded, cylindrical pedestal (height, $1.7 \mathrm{~mm}$; diameter, $3.5 \mathrm{~mm}$ ). The microthermocouple wire was attached to terminating connector pins (Omega Engineering), and dental acrylic was used to encase the cryoloop tubes, pedestal, and microthermocouple assembly. A detailed description of cryoloop manufacturing and operation is provided by Lomber et al. (1999).

Rats were placed under general, surgical-plane anesthesia with ketamine hydrochloride (100 mg/kg, i.p.) and xylazine ( $5 \mathrm{mg} / \mathrm{kg}$, i.p.), and fixed in a stereotaxic instrument (Kopf) with the incisor bar set to skull 


\section{Short-duration ICMS}

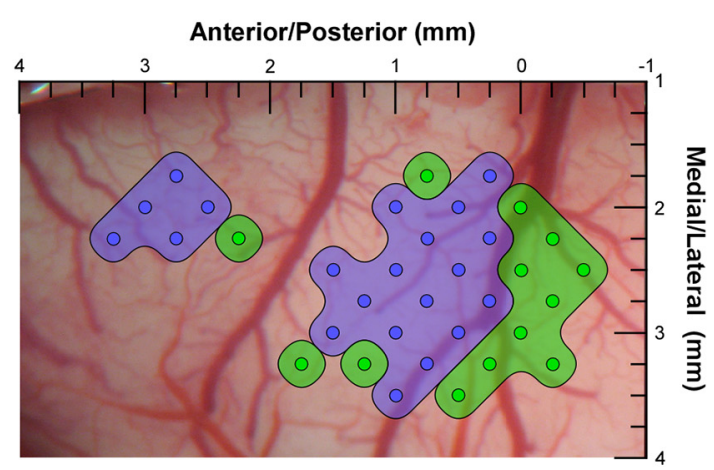

\section{Long-duration ICMS}

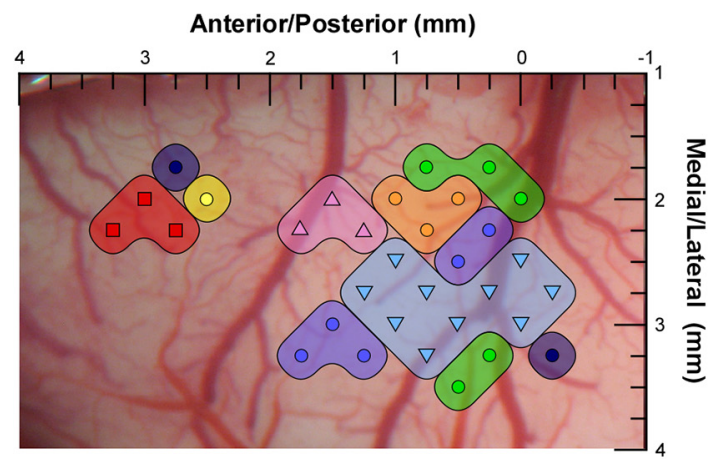

\section{Forelimb movements}

\section{Simple}

\section{Digit flexion \\ - Elbow extension \\ - Elbow flexion \\ ○ Wrist extension}

\section{Complex}

$\square$ Elevate
$\square$ Advance
$\square$ Grasp
$\square$ Retract

Figure 3. Representative forelimb movement representation topography derived in the same rat with short-duration intracortical microstimulation preceding the long-duration intracortical microstimulation. The duration of stimulation trains alters the evoked forelimb responses elicited within the RFA and CFA. Complex movements, involving coordinated activity among multiple forelimb joints, are observed under long-duration microstimulation. Nonresponsive or nonforelimb points were observed to completely surround the responsive area.

flat. Supplemental injections of either ketamine $(25 \mathrm{mg} / \mathrm{kg})$ or a mixture of ketamine $(17 \mathrm{mg} / \mathrm{kg})$ and xylazine $(2 \mathrm{mg} / \mathrm{kg})$ were given intraperitoneally as required throughout surgery to maintain a constant level of anesthesia, as determined by monitoring vibrissae whisking, breathing rate, and foot and tail reflex in response to a gentle pinch. The local anesthetic lidocaine (2\%) was administered subcutaneously at the incision site in the scalp. The skull was exposed, a partial craniotomy of frontal bones was made over the sensorimotor neocortex, and dura reflected. Five stainless steel jeweler screws were placed in the skull adjacent to the craniotomy to permit firm anchoring of the cryoloop headcap assembly.

The cryoloop assembly was disinfected with $70 \%$ ethanol and positioned in place over the exposed neocortex, resting on the pial surface. Loops targeting the RFA were implanted $3.0 \mathrm{~mm}$ anterior to bregma and $1.5-3.5 \mathrm{~mm}$ lateral to midline. CFA loops were implanted $0.75 \mathrm{~mm}$ anterior to bregma and $1.75-3.75 \mathrm{~mm}$ lateral to midline (Fig. $1 d$ ). Dura was replaced, and a silicone elastomer (Kwik-Sil, World Precision Instruments) was used to fill the cranial vault. Dental acrylic was used to secure the cryoloop assembly to the skull and screws. The scalp was sutured around the cryoloop and acrylic headcap, and rats were given a topical application of Xylocaine jelly (2\%) analgesic around the incision. The surgical procedure to implant cryoloops, their presence in contact with the cortex, and their repeated operation has been shown to disrupt neither the structural nor functional integrity of the cerebrum (Lomber and Payne, 1996; Lomber et al., 1999; Yang et al., 2006). We verified that cryoloop implantation and operation in the present study was not associated with alterations in the cortical area eliciting forelimb movements compared with unimplanted controls.

Loop dimensions, holding temperature, and implantation coordinates were chosen to provide effective deactivation of the CFA or RFA with minimal overlap. Acute cortical temperature recordings revealed an effective isotherm for cortical deactivation $\left(20^{\circ} \mathrm{C}\right.$; Lomber et al., 1999; Coomber et al., 2011; Antunes and Malmiera, 2011) in layer $\mathrm{V}$ at a distance of 1 $\mathrm{mm}$ from the cryoloop with a holding loop temperature of $4^{\circ} \mathrm{C}$ (Fig. $\left.1 b, c\right)$. We confirmed effective cortical deactivation by verifying that ICMS-evoked forelimb motor responses were abolished during cooling to $<20^{\circ} \mathrm{C}$ and returned when rewarmed. Implantation coordinates were obtained from unimplanted rats in which long-duration ICMS-generated forelimb movement representations $(n=10)$ were localized relative to bregma with a mean CFA of $0.88 \mathrm{~mm} / 2.71 \mathrm{~mm}$ (anterior/posterior, medial/lateral; range, 2.50 to -0.75 and $1.75-4.50$ $\mathrm{mm}$ ) and a mean RFA of $3.11 \mathrm{~mm} / 2.30 \mathrm{~mm}$ (anterior/posterior, medial/lateral; range, $4.25-2.00$ and $1.5-2.5 \mathrm{~mm}$ ). Cooling deactivation in this experiment would be expected to effectively block synaptic transmission completely in the RFA and nearly completely $(>90 \%)$ in the CFA with minimal overlap between the two.

Cooling deactivation. The cortex was cooled by pumping chilled methanol from a methanol/ dry ice bath mixture through Teflon tubing connected to cryoloop inlet/outlet tubes with a reciprocating piston pump (QG150-Q1-CSC, Fluid Metering Inc.) to maintain a constant loop temperature of $4^{\circ} \mathrm{C}$. Loop temperature was monitored (HH-25TC digital thermometer, Omega Engineering) and controlled to $\pm 1^{\circ} \mathrm{C}$ of the desired value by controlling the rate of methanol flow. Cooling deactivation was terminated by stopping methanol flow and allowing passive rewarm of the cortex.

Single-pellet testing. Following cryoloop implantation, five 15 min reaching sessions were provided for acclimation to the task under sham cooling with tubingattached cryoloops. Three testing sessions were performed on separate days, and the data were pooled. Rats were given 5 min within each cooling cycle to perform as many trials as possible. In addition to endpoint measures of percentage of success and the number of reach attempts, a qualitative rating of reaching performance was manually conducted using frame-by-frame analysis of video recordings according the criteria of Whishaw et al. (2003), permitting accurate assessment of the integrity of individual components of the behavior that can be difficult to achieve with automated techniques (Lamoreux, 1996). Reaching behavior was broken down into 10 discrete subcomponents that were assessed according to the following ordinal rating scale: (1) digits to the midline (the reaching limb is lifted from the floor so that the tips of the digits are aligned with the midline of the body); (2) digits semiflexed (as the limb is lifted, the digits are maintained in a semiflexed position); (3) elbow to midline (the elbow is adducted to the midline while the tips of the digits retain their alignment with the midline of the body); (4) advance (the limb is advanced directly through the slot toward the food pellet); (5) digits extend (the digits extend during the advance so that the digit tips are pointing toward the target); (6) arpeggio (while the forelimb is over the target, the hand pronates from digit 5 , the outer digit, through to digit 2 while the hand simultaneously opens; (7) grasp (the digits flex with the hand closing over the pellet, and the wrist extends slightly); (8) supination I (as the limb is withdrawn, the hand supinates by nearly $90^{\circ}$ to allow withdrawal through the slot); (9) supination II (once withdrawn from the slot, the hand further supinates by nearly $45^{\circ}$ to place the food in the mouth); and (10) release (the hand contacts the mouth and opens to release the food). Movements that appeared normal were given a score of 0 ; ambiguous movements, a score of 0.5 ; impaired but recognizable 
Table 1. Forelimb motor map topography: movement representation size and localization

\begin{tabular}{|c|c|c|c|}
\hline Forelimb movement & $\begin{array}{l}\text { Cortical area } \\
\left(\mathrm{mm}^{2}\right)\end{array}$ & $\begin{array}{l}\text { AP coordinates }^{a} \\
(\mathrm{~mm})\end{array}$ & $\begin{array}{l}\text { ML coordinates }^{b} \\
(\mathrm{~mm})\end{array}$ \\
\hline \multicolumn{4}{|l|}{ Naive group } \\
\hline \multicolumn{4}{|l|}{ Complex } \\
\hline Elevate & $0.575 \pm 0.175$ & $0.689 \pm 0.116$ & $2.396 \pm 0.158$ \\
\hline Grasp & $0.513 \pm 0.090$ & $3.191 \pm 0.107$ & $2.326 \pm 0.089$ \\
\hline Reach & $0.413 \pm 0.095$ & $1.547 \pm 0.170$ & $2.283 \pm 0.102$ \\
\hline Retract & $1.025 \pm 0.058$ & $0.808 \pm 0.070$ & $3.165 \pm 0.072$ \\
\hline \multicolumn{4}{|l|}{ Simple } \\
\hline Digit flexion & $0.288 \pm 0.070$ & $3.238 \pm 0.101$ & $2.200 \pm 0.102$ \\
\hline Elbow extension & $0.194 \pm 0.059$ & $1.141 \pm 0.480$ & $2.447 \pm 0.399$ \\
\hline Elbow flexion & $1.613 \pm 0.194$ & $1.115 \pm 0.122$ & $2.682 \pm 0.096$ \\
\hline Supination & $0.025 \pm 0.025$ & $0.000 \pm 0.000$ & $1.875 \pm 1.875$ \\
\hline Wrist extension & $0.663 \pm 0.062$ & $0.538 \pm 0.196$ & $2.887 \pm 0.143$ \\
\hline \multicolumn{4}{|l|}{ Reach-trained group } \\
\hline \multicolumn{4}{|l|}{ Complex } \\
\hline Elevate & $0.694 \pm 0.140$ & $0.794 \pm 0.114$ & $2.420 \pm 0.085$ \\
\hline Grasp & $0.472 \pm 0.083$ & $3.261 \pm 0.039$ & $2.511 \pm 0.068$ \\
\hline Reach & $0.667 \pm 0.143$ & $1.616 \pm 0.112$ & $2.500 \pm 0.084$ \\
\hline Retract & $1.111 \pm 0.183$ & $0.631 \pm 0.085$ & $3.347 \pm 0.085$ \\
\hline \multicolumn{4}{|l|}{ Simple } \\
\hline Digit flexion & $0.306 \pm 0.059$ & $3.101 \pm 0.087$ & $2.461 \pm 0.115$ \\
\hline Elbow extension & $0.167 \pm 0.059$ & $0.615 \pm 0.342$ & $2.694 \pm 0.095$ \\
\hline Elbow flexion & $1.097 \pm 0.209$ & $1.360 \pm 0.053$ & $3.082 \pm 0.080$ \\
\hline Supination & $0.056 \pm 0.056$ & $2.063 \pm 2.063$ & $4.188 \pm 0.000$ \\
\hline Wrist extension & $0.444 \pm 0.066$ & $0.962 \pm 0.320$ & $2.893 \pm 0.175$ \\
\hline
\end{tabular}

Data are reported as the mean \pm SEM. AP, Anteroposterior; ML, mediolateral.

${ }^{a}$ Coordinates are referenced to bregma in the coronal plane.

${ }^{b}$ Coordinates are referenced to the sagittal suture.

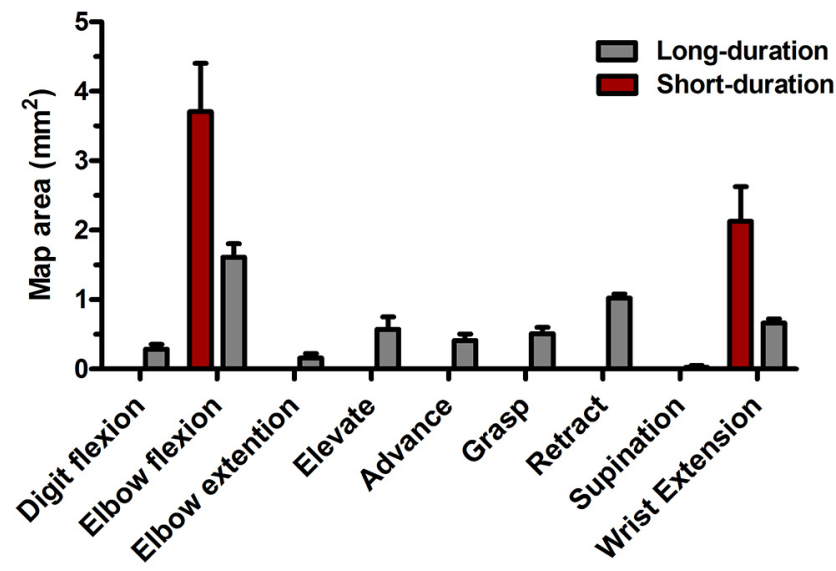

Figure 4. Comparison of forelimb movements and representational areas (in square millimeters) evoked with SD-ICMS and LD-ICMS. Size distribution of forelimb movements elicited under SD-ICMS and LD-ICMS. Elbow flexions are the most common movement elicited under both stimulation conditions.

movements, a score of 1 ; and absent or unrecognizable movements, a score of 2 . The first five successful reaches per rat per cooling condition were assessed. The mean $( \pm$ SEM) percentage of success, number of reaches, and error score for each movement subcomponent across trials of each cooling cycle were used for analyses.

Vermicelli pasta handling. Rats were trained for $5 \mathrm{~d}$ in a transparent acrylic cylinder $(20 \mathrm{~cm}$ diameter and $30 \mathrm{~cm}$ height) to consume an unlimited amount of uncooked vermicelli strands $(7 \mathrm{~cm}$ length, $1.5 \mathrm{~mm}$ diameter; Primo) in 20 min sessions. The cylinder rested on a glass shelf with a mirror placed beneath it at a $90^{\circ}$ angle to permit simultaneous views facing and underneath the cylinder to record forelimb use when the rat was turned away from the camera. To acclimate rats to pasta handling, five strands of vermicelli were provided in their home cages several days a

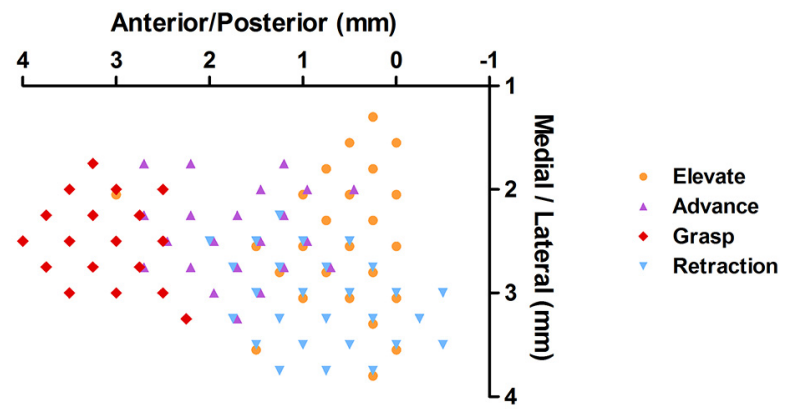

b

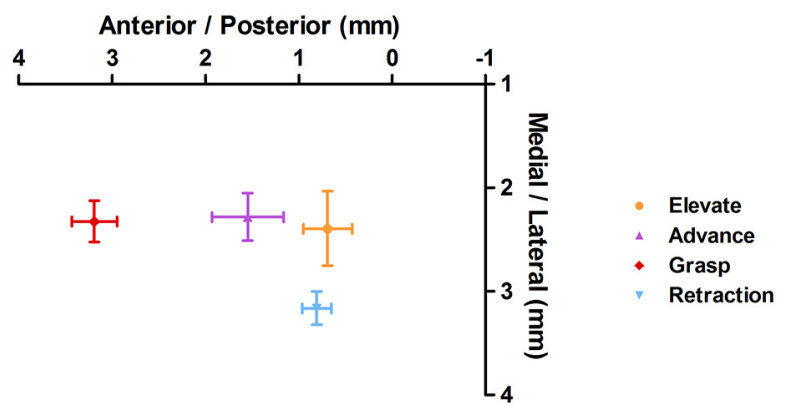

Figure 5. Complex movement representation topography elicited under LD-ICMS. $\boldsymbol{a}, \boldsymbol{b}, \mathrm{Cu}$ mulative distribution (a) and $95 \%$ confidence intervals $(\boldsymbol{b})$ in 10 naive rats. Complex movements exhibit a topographical clustering across motor cortex: gasping movements are localized most anterior and are exclusive to the RFA; advances are elicited caudally from grasps; retractions are typically elicited from the posterior lateral aspect of the CFA; elevations are elicited predominantly from the posterior medial aspect of the CFA.

before testing. Testing occurred on the sixth day of training in which rats were presented with five vermicelli strands under each cooling cycle. The vermicelli asymmetry ratio (Allred et al., 2008) was used to quantify forelimb motor performance and was defined as [(number of contralateral adjustments/total number of contralateral and ipsilateral forelimb adjustments $) \times 100$ ]. Forelimb adjustments consisted of $(1)$ hand release or recontact of the strand, (2) reformation of the hand hold, or (3) digit extension/flexion or abduction/adduction. The audible sounds made when rats are eating pasta were used to determine eating onset/offset. The mean $( \pm$ SEM) across the five trials of each cooling cycle were used for analyses.

Intracortical microstimulation. Standard ICMS techniques were adapted to generate detailed maps of forelimb regions of the motor cortex (Nudo et al., 1990; Kleim et al., 1998; Young et al., 2011). Rats were anesthetized with ketamine hydrochloride $(100 \mathrm{mg} / \mathrm{kg}$, i.p. $)$ and xylazine $(5 \mathrm{mg} / \mathrm{kg}$, i.p.) and secured in a stereotaxic frame with the incisor bar set to skull flat. Supplemental injections of either ketamine $(25 \mathrm{mg} / \mathrm{kg})$ or a mixture of ketamine $(17 \mathrm{mg} / \mathrm{kg})$ and xylazine $(2 \mathrm{mg} / \mathrm{kg})$ were given intraperitoneally, as required, throughout surgery to maintain a constant level of anesthesia, as determined by monitoring vibrissae whisking, breathing rate, and foot and tail reflex in response to a gentle pinch.

A $7 \times 5 \mathrm{~mm}$ craniotomy was performed over the left sensorimotor cortex. For reach-trained rats, the craniotomy was performed contralateral to the trained limb. The window extended approximately between 5 $\mathrm{mm}$ anterior to and $2 \mathrm{~mm}$ posterior to bregma, and from midline to 5 $\mathrm{mm}$ lateral of midline. A small puncture was made in the cisterna magna to reduce cortical edema. Dura was removed, and silicone fluid (Factor II) heated to body temperature was used to cover the cortical surface. A $42 \times$ image of the exposed portion of the brain was captured using a digital camera (Canon Canada Inc.) coupled to a Stemi 2000-C stereomicroscope (Carl Zeiss), and displayed on a personal computer. A grid of $500 \mu \mathrm{m}$ squares was then overlaid on the digital image using Canvas imaging software (version 9.0.1; ACD systems Inc.), and was calibrated to bregma using midline and frontal suture intersections obtained before 
a
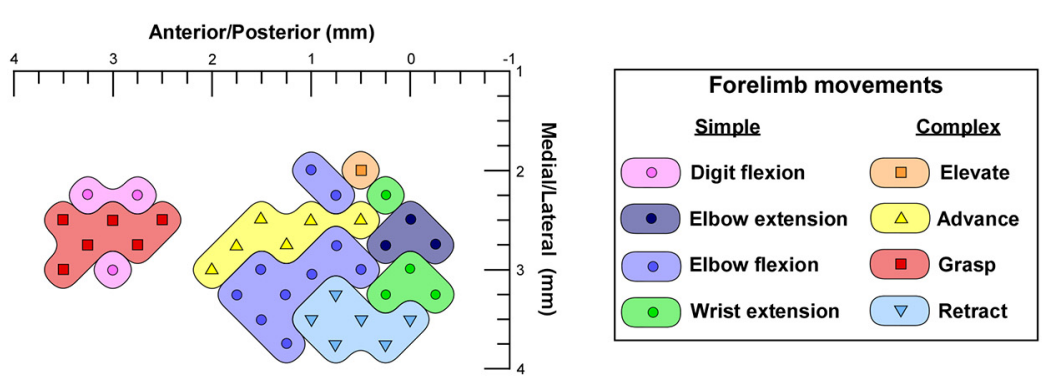

b
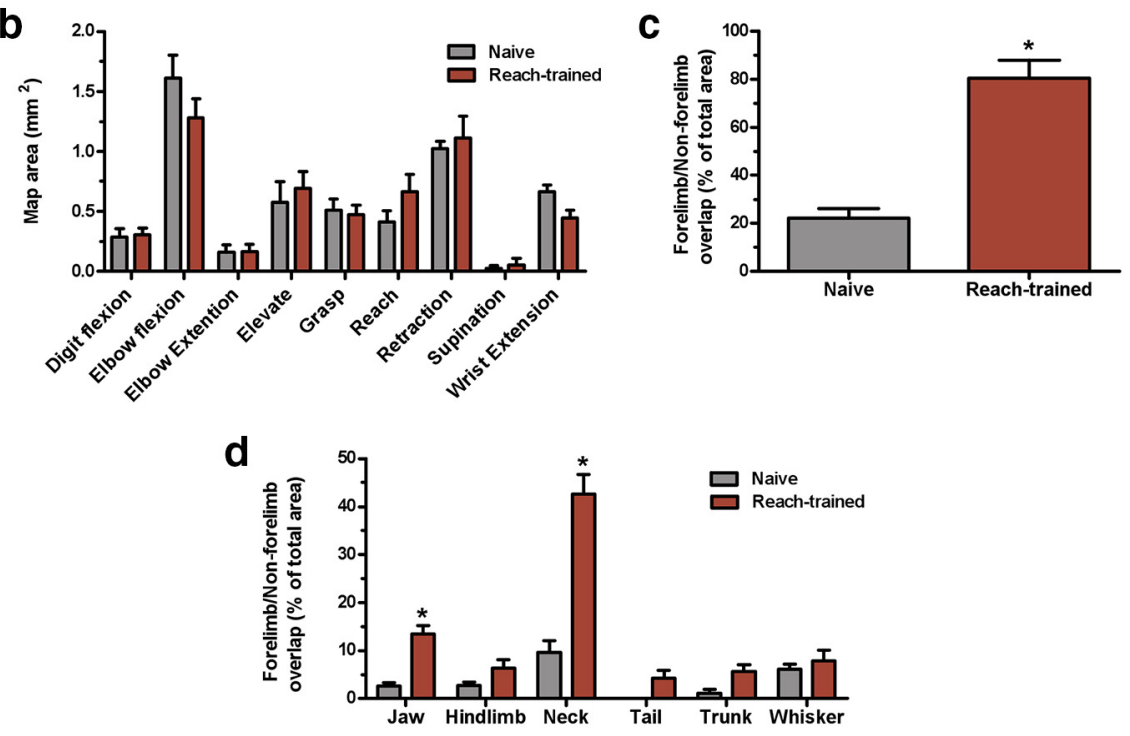

Figure 6. Forelimb movement representations following skilled reach training. $\boldsymbol{a}$, Representative forelimb movement representation topography derived in a reach-trained rat. $\boldsymbol{b}$, Reach-trained rats did not demonstrate any specific increase in individual movement representation size relative to naive controls. $c$, Although forelimb representation sizes between groups were equivalent, there was a significant $(p=0.0001$ ) increase in the proportion of forelimb movement representations that also elicited nonforelimb movements following training. $\boldsymbol{d}$, Post hoc analyses revealed that jaw $(p=0.0022)$ and neck $(p=0.0001)$ movements overlapping within the forelimb movement representations in reach-trained rats were significantly increased. ${ }^{*} p<0.05$.

the craniotomy. Penetrations were performed at the intersections of the grid lines and in the center of each square to give an interpenetration distance of $354 \mu \mathrm{m}$, except when located over a large blood vessel, in which case a penetration was not performed.

Glass-coated platinum/iridium microelectrodes with an input impedance of $0.5 \pm 0.1 \mathrm{M} \Omega(1000 \mathrm{~Hz}, 10 \mathrm{nA})$ were used (FHC Inc.) were used. Electrode impedance was monitored throughout mapping experimentation, and electrodes were discarded when impedance measurements dropped below $0.3 \mathrm{M} \Omega$. Electrodes were guided into the neocortex to a depth of $1550 \mu \mathrm{m}$ via microdrive (Narishige), corresponding to the somatic region of neocortical layer $\mathrm{V}$ pyramidal neurons (Teskey et al., 2002). Movements can be readily elicited within a large (1550 $\pm 150 \mu \mathrm{m}$ depth from surface) profile of forelimb sensorimotor cortex with negligible effect on their nature or threshold (Young et al., 2011). An isolated pulse stimulator (model 2100, A-M Systems) was used to deliver electrical current. A ground stimulation lead was placed in contact with exposed neck musculature from the incision to puncture the cisterna magna. Current output reliability was measured via the voltage drop across a $1 \mathrm{k} \Omega$ resistor connected in series with the return lead to the stimulator. Two stimulation protocols were used. Short-duration microstimulation consisted of $39 \mathrm{~ms}$ trains of $200 \mu \mathrm{s}$ biphasic (cathodal lead) pulses, delivered at a frequency of $333 \mathrm{~Hz}$ and an intensity of $100 \mu \mathrm{A}$. Pulse trains were repeated at $1 \mathrm{~Hz}$ intervals until a movement was evoked or up to a maximum of 10 trains. Long-duration microstimulation consisted of $500 \mathrm{~ms}$ trains of $200 \mu \mathrm{s}$ biphasic (cathodal lead) pulses, delivered at a frequency of $333 \mathrm{~Hz}$ and an intensity of $100 \mu \mathrm{A}$. Biphasic current was used to minimize damage that could occur during long-duration stimulation trains (Asanuma and Ward, 1971; Graziano et al., 2002). Pulse trains were delivered in $0.2 \mathrm{~Hz}$ intervals (up to a maximum of six per site) to ensure the stability of evoked responses.

Rats were placed in a stereotaxic frame and supported in a limb-free prone position with forelimbs hanging down and free to move in all directions. Between stimulation trials, forelimb resting position was reset to a semiextended state with the wrist palm down and digits semiextended (Fig. 2). Following the first stimulation site aimed at the center of the CFA, subsequent stimulations followed in the parasagittal direction until either a nonforelimb or nonresponsive point was observed. Mapping commenced in this row-by-row fashion on the overlaid grid until a border of nonforelimb and/or nonresponsive points was created. Nonresponsive sites were defined as those that failed to elicit a forelimb movement on more than half of the delivered stimulation trains, up to a maximum of six. Forelimb map boundaries were defined by mapping all adjacent sites to a nonforelimb or nonresponsive point. Throughout the surgery, anesthetic levels were monitored by verifying evoked movements in previously defined positive-response sites and to map borders of nonresponsive points.

Movement classification and motor map topography. Movements were monitored visually during electrophysiological mapping and video recorded for subsequent analysis (30 frames/s, $1000 \mathrm{~Hz}$ shutter speed; HDC-HS60 camera, Canon). A light-emitting diode synchronized with stimulator output was fixed to the stereotaxic frame in the camera field of view. Video-recorded movements were characterized with VLC software (http://www. videolan.org). Frame-by-frame analysis of digitized joint positions with ImageJ (National Institutes of Health) and Canvas imaging software (version 9.0.1; ACD Systems Inc.) was used when movements were too difficult to visually characterize, and for determining the effect of varying stimulation duration and intensity on movement amplitude and sequencing.

Forelimb map topography was assessed by analyzing the nature, number, and location (referenced to bregma) of response-positive stimulation sites. The Canvas imaging software was used to record the location of stimulation sites in frontal and sagittal planes using a grid of $500 \mu \mathrm{m}$ squares, calibrated to bregma, overlaid on the digital photograph of the cortical surface. Penetrations were performed at the intersections of the grid lines and in the center of each square to give an interpenetration distance of $354 \mu \mathrm{m}$. Each responsive site was taken to represent 0.125 $\mathrm{mm}^{2}$ of cortical surface $(354 \times 354 \mu \mathrm{m})$.

Statistical analyses. ANOVA was performed on movement representation topography analyses with Tukey's post hoc tests for multiplecomparison testing. Independent Student's $t$ tests were used in single-measure two-sample comparisons of forelimb map area measurements, and drug doses were delivered during ICMS. One-way repeatedmeasures ANOVA was performed on behavior analysis for endpoint single-pellet reaching and vermicelli handling measures for RFA-cooled and CFA-cooled groups. Dunnett's post hoc tests contrasting cooling and rewarm conditions to baseline were performed when a significant main effect was observed. Paired-samples $t$ tests were used to assess reachtraining progression between the first and last $3 \mathrm{~d}$ of single-pellet pretraining, as well as preimplantation and postimplantation reaching success. Kruskal-Wallis tests with post hoc Mann-Whitney $U$ tests 
a

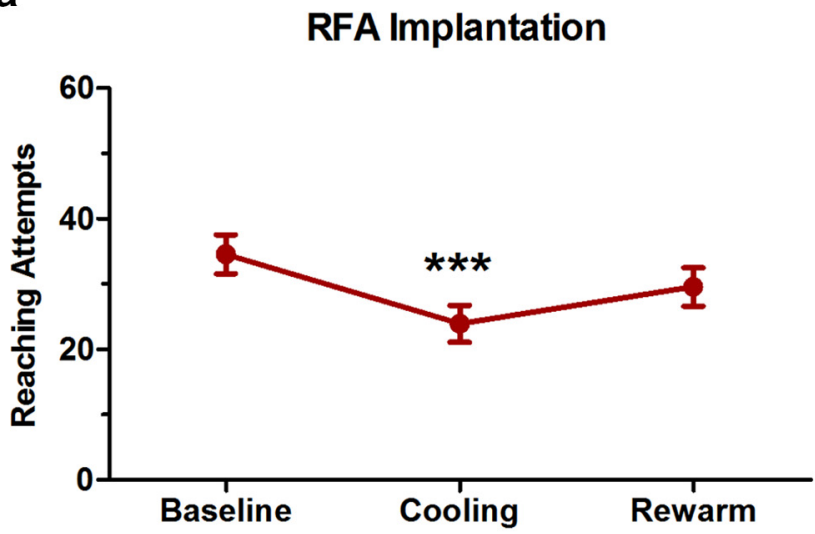

C

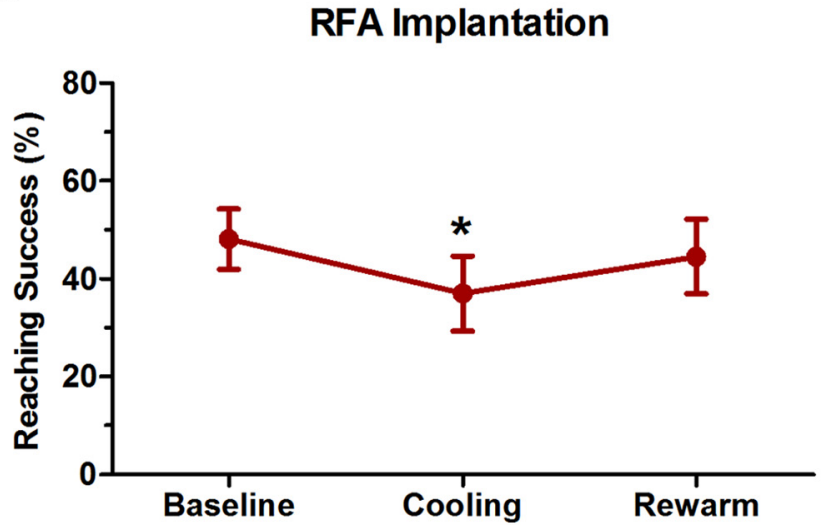

b

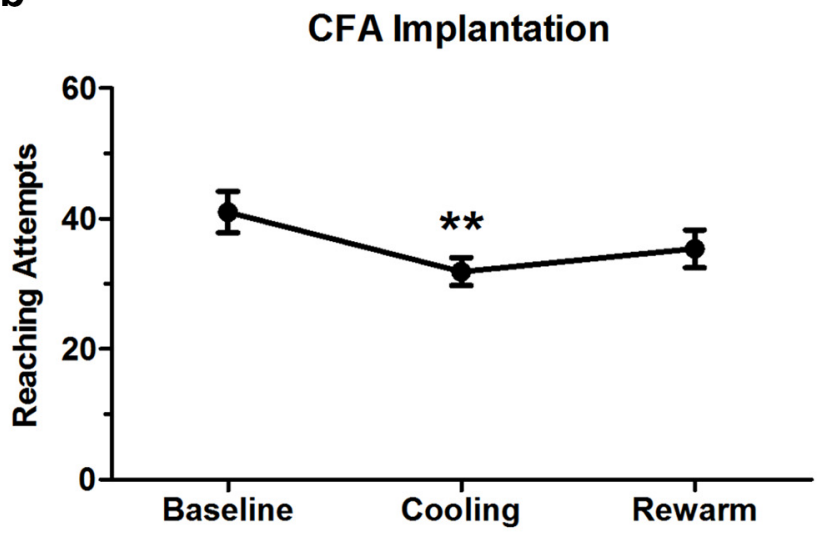

d

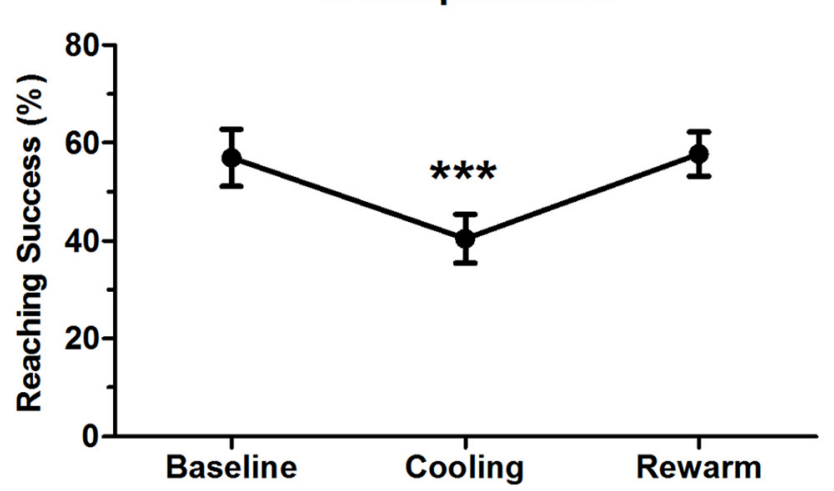

Figure 7. Single-pellet reaching endpoint success and attempts. Behavioral performance with repeated testing sessions under baseline, cortical cooling, and rewarm conditions. $\boldsymbol{a}-\boldsymbol{d}$, Cortical cooling was associated with significant reductions in mean ( \pm SEM) reaching attempts and success in both RFA-cooled $(\boldsymbol{a}, \boldsymbol{c})$ and (FA-cooled $(\boldsymbol{b}, \boldsymbol{d})$ groups. ${ }^{*} p<0.05,{ }^{* *} p<0.01,{ }^{* * *} p<0.001$.

were used to assess cooling-induced (i.e., cooling - baseline error scores) differences in reach subcomponent error scores between RFAcooled and CFA-cooled groups. Comparison testing was performed only when significant main effects were observed. All analyses were two tailed. An experiment-wide a priori $\alpha$ level of 0.05 was used. Statistical analyses were conducted using GraphPad Prism 6. Data are presented as the mean \pm SEM unless otherwise noted. Asterisks in figures represent significance level, as follows: ${ }^{*} p<0.05{ }^{* *} p<0.01$, and ${ }^{* * *} p<0.001$.

\section{Results}

Characterization of forelimb movements and cortical movement topography derived from long-duration intracortical microstimulation

A total of 377 forelimb-responsive sites in 10 experimentally naive Long-Evans rats was probed using LD-ICMS. Nine distinct forelimb movement patterns were observed and are depicted in Figure 2. Movements were characterized as either simple, when involving muscle contraction about a single joint, or complex, when involving muscle contraction about multiple joints. Simple movements predominantly involved flexions of the elbow or digits and extensions of the wrist. Less commonly observed simple movements consisted of forelimb supination or extensions of the elbow. Simple movements were similar to the brief twitches commonly observed with short-duration ICMS (Neafsey et al., 1986); however, muscle contractions were maintained for the duration of the $500 \mathrm{~ms}$ stimulation trains. Four large areas of complex, multiple joint, forelimb movements were reliably observed and were classified as follows: (1) advances (rostral displacement of the forelimb involving flexions of the shoulder and elbow, and extension of the wrist); (2) elevations (by combined flexion of the elbow and extension of the wrist); (3) grasps (flexion of the wrist and complete contraction of the digits); and (4) retractions (caudal displacement of forelimb involving shoulder extension, elbow flexion, and wrist extension).

A clear topography of complex movement representations was found with LD-ICMS (Fig. 3; see Fig. 5). Grasping movements were situated most anterior and exclusively in the RFA. Mean coordinates of grasp-responsive stimulation sites were found to be $3.2 \pm 0.1 \mathrm{~mm}$ anterior to bregma. Advances were concentrated in the anterior aspect of CFA $(1.5 \pm 0.2 \mathrm{~mm})$. Retractions $(0.8 \pm 0.1 \mathrm{~mm})$ and elevations $(0.7 \pm 0.1 \mathrm{~mm})$ were clustered along the lateral and medial posterior aspects of CFA, respectively. Simple movement representations were found to be distributed within CFA and RFA with no clear topography, with the exception of digit flexions, which were exclusively localized to the RFA (Fig. 3; see Fig. 5). Topographic quantification of all movement area sizes and locations is provided in Table 1. A cumulative distribution of movement representations from 10 rats is provided in Figure 5.

To contrast forelimb movement topography derived under both stimulation protocols, three rats were mapped first under SD-ICMS followed by LD-ICMS in the same session. A representative motor map is provided in Figure 3. A total forelimb map was not found to differ between LD-ICMS $\left(5.3 \pm 0.4 \mathrm{~mm}^{2}\right)$ and 


\section{RFA Implantation}

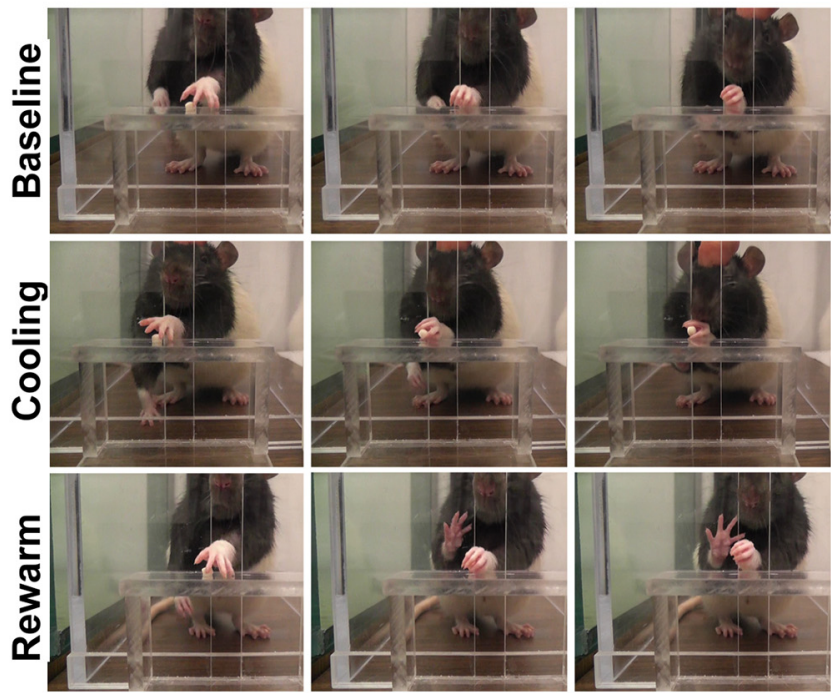

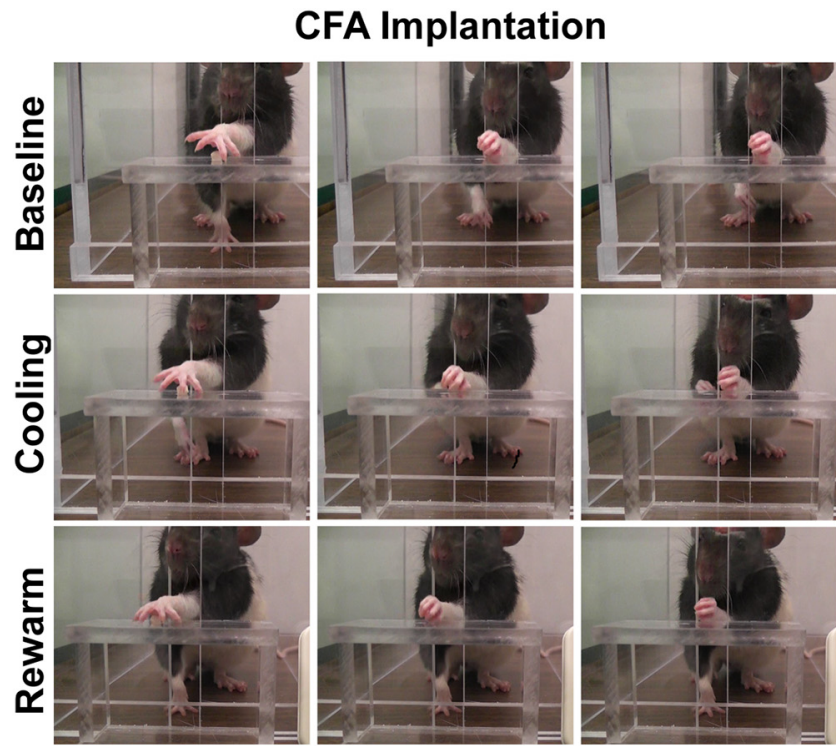

CFA Implantation
RFA Implantation
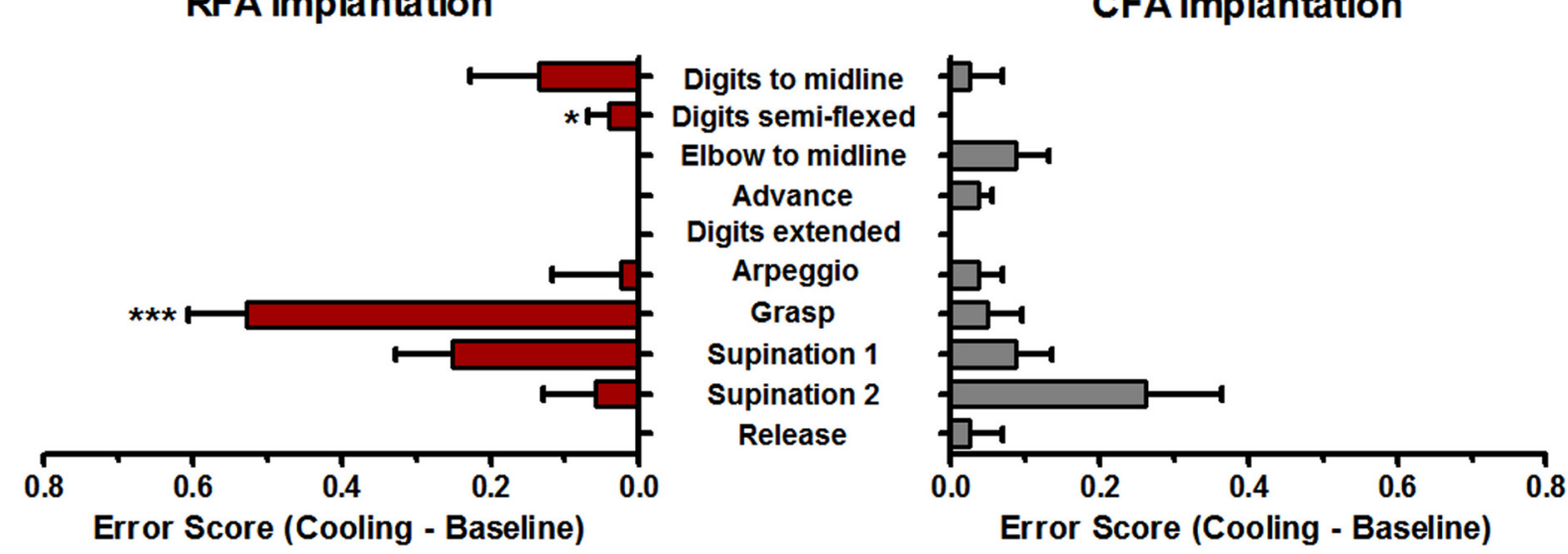

Figure 8. Qualitative comparison of the grasping movement subcomponent in representative rats during acute cooling of the RFA and CFA. Under baseline and rewarm conditions, rats in both groups typically clasp the food pellet securely within the hand. During cooling deactivation of the RFA, food pellets were often held between digits. A significant increase in the mean ( $\pm S E M$ ) error score of the grasping movement was observed during cooling (baseline error scores subtracted) of the RFA compared with the CFA. ${ }^{*} p<0.05,{ }^{* * *} p<0.001$.

SD-ICMS $\left(5.0 \pm 0.7 \mathrm{~mm}^{2}\right)$ protocols $\left(t_{(11)}=0.37, p=0.719\right.$; Figs. 3, 4, 5). Complex movements were found exclusively with LD-ICMS and accounted for $52.2 \pm 2.8 \%$ of all responsive forelimb sites (Fig. 4).

Forelimb movement representation topography following skilled motor learning

Skilled motor learning has been previously associated with a reorganization of forelimb movement representations elicited under SD-ICMS (Kleim et al., 1998), but not LD-ICMS (Ramanathan et al., 2006). We next derived complex movement representations following the acquisition of a skilled reaching task to ensure that grasping representations remained exclusive to the RFA. Rats were trained for $14 \mathrm{~d}$ on the single-pellet reaching task, and movement representations were derived under LD-ICMS (Fig. 6). Motor learning was demonstrated by significant increases in the number of reach attempts $\left(t_{(16)}=6.8, p=0.0001\right)$ and the success rates of reach attempts $\left(t_{(16)}=4.9, p=0.0002\right)$ during training. Reach training was found to effect neither the nature nor the quality of complex forelimb movements. All complex and simple forelimb movements found in reach-trained rats were observed in untrained controls. Similarly, reach training did not alter either the size or location of forelimb movement representations (all $p>0.05$; Table 1 ).

Although complex forelimb movement representations were unaltered following skilled motor learning, reach training was associated with a significant $\left(F_{(11,102)}=38.87, p=0.0001\right)$ increase in nonforelimb movements elicited within forelimb movement representations (neck, jaw, whisker, tail, trunk, or hindlimb; Fig. $6 c, d$ ). A mean of $80.4 \pm 7.6 \%$ of forelimbresponsive stimulation sites in reach-trained rats were dual responsive for nonforelimb movements compared with $22.2 \pm$ $4.0 \%$ in untrained controls. The increased overlap of nonforelimb-responsive sites within the forelimb motor map were attributed to significant increases in neck $(42.6 \pm 4.1 \%, p=$ $0.0001)$ and jaw $(13.5 \pm 1.7 \%, p=0.0022)$ representations observed in trained rats relative to untrained controls $(9.7 \pm 2.5 \%$ and $2.6 \pm 0.7 \%$, respectively). These differences were not found to be attributed to group differences in the amount of ketamine $\left(t_{(17)}=1.37, p=0.189\right)$ or xylazine $\left(t_{(17)}=0.17, p=0.865\right)$ anesthesia administered during microstimulation 


\section{RFA Implantation}
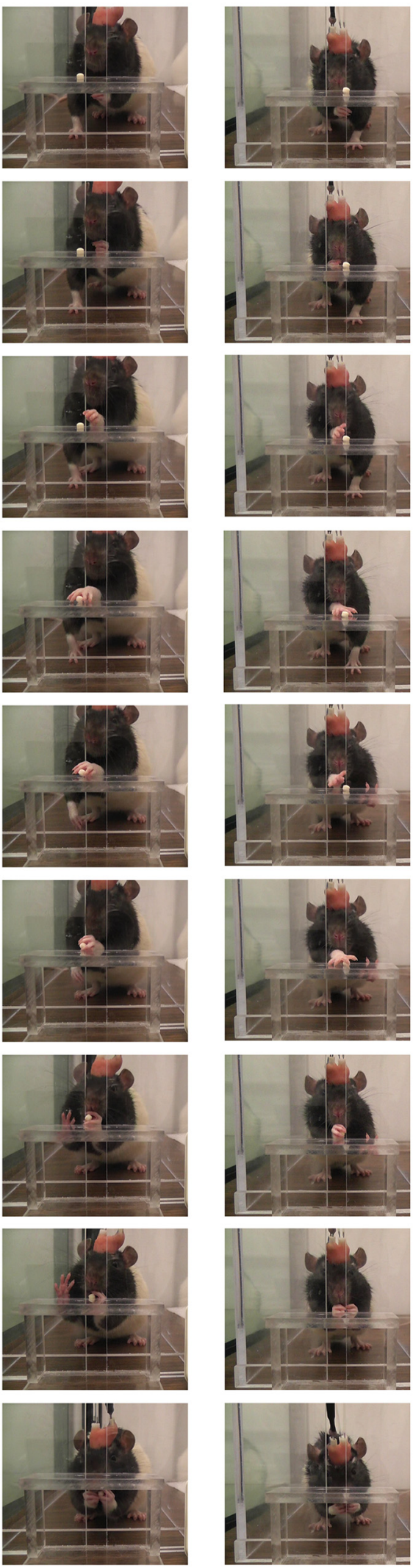

Figure 9. Sample reach attempt video frame stills during a successful reach in a RFA-cooled rats (left) and (FA-cooled rats (right). RFA-cooled rats did not fully clasp the food pellet within the hand without significant impairment to limb advancement and pellet retrieval. CFA-cooled rats exhibited deficits in adduction of the elbow and limb advancement without significant impairment to grasping of the pellet.

\section{Behavioral assessment during selective and reversible} cortical deactivation

We next sought to determine whether the silencing of grasping representations in the RFA would lead to specific deficits in grasping movement ability in the behaving rat. Cortical cooling deactivation delivered via chronically implanted cryoloops (Lomber et al., 1999) was used to investigate the result of selective, reversible deactivation of grasping representations, located exclusively within the RFA, on grasping performance in the single-pellet skilled reaching and vermicelli-handling tasks. To ensure that any observed behavior deficits were not a consequence of nonspecific inactivation of forelimb motor areas, a second group of rats received cryoloop implantations targeting reaching (elevate/advance/retract) representations located in the CFA.

Deactivation of either the RFA or the CFA resulted in expected deficits in reaching attempts and success during the cooling cycle compared with baseline and rewarm conditions (all $p<0.05$; Fig. 7) When a qualitative assessment of reaching performance in successful trials was conducted, however, a specific deficit in the grasping subcomponent was observed in RFA-cooled rats (Fig. 8 ). Cooling deactivation of the RFA was associated with significantly higher mean error scores $(0.527 \pm 0.0785 ; U=1.00 ; p=$ 0.0002 ), relative to baseline, in the grasp subcomponent of reaching compared with CFA (0.050 \pm 0.046$)$. Under baseline and rewarm conditions, RFA-cooled rats typically clasped the food pellet securely within the hand. During cooling deactivation of the RFA, food pellets were often held precariously between digits 2 and 3 or 4 and 5 (Figs. 8, 9). In CFA-cooled rats, successful trials demonstrated trends of increased mean error scores for elbow to midline $(U=22.5, p=0.0597)$ and advance $(U=22.5, p=$ $0.0586)$ subcomponents $(0.088 \pm 0.044$ and $0.038 \pm 0.018$, respectively) relative to RFA-cooled rats $(0.0 \pm 0.0$ and $0.0 \pm 0.0$, respectively). During cooling deactivation of the CFA, the elbow was not consistently adducted toward midline, requiring an adjustment of reaching postures. Advances in three CFA-cooled rats were also found to terminate prematurely, requiring a second advancement movement before arpeggio and grasping (Fig. 9). No significant error score differences found were found between groups for the remaining reach movement subcomponents (all $p>0.05$; Fig. 8). Further, no differences were observed between preimplantation success rates and postimplantation success rates in the baseline cooling cycle in either group (all $p>0.05$ ).

A significant deficit in the vermicelli-handling task was also observed in RFA-cooled rats, but not in CFA-cooled rats. RFAcooled rats exhibited a significant reduction in contralateral hand reflected by reduced asymmetry ratios during cooling relative to baseline $(p=0.0001)$. Decreased asymmetry ratios in RFAcooled rats were specific to the cooling phase and recovered to baseline values during the rewarm cycle $(p>0.997)$. No differences in the asymmetry ratios in CFA-cooled rats were observed among baseline, cooling, and rewarm testing (all $p>0.05$ ).

\section{Cryoloop placement verification and movement representation viability}

Following behavioral testing, rats were subjected to longduration ICMS to verify the integrity of cortical movement representations and appropriate cryoloop placement targeting the CFA and RFA forelimb areas. In two rats, movement representations were unable to be derived due to a headcap loss following testing (RFA group) and cortical damage arising from cryoloop extirpation (CFA group). In all other cases, the cortex was viable, allowing forelimb movement derivation of both forelimb areas, which were found to be located within expected cooling deacti- 

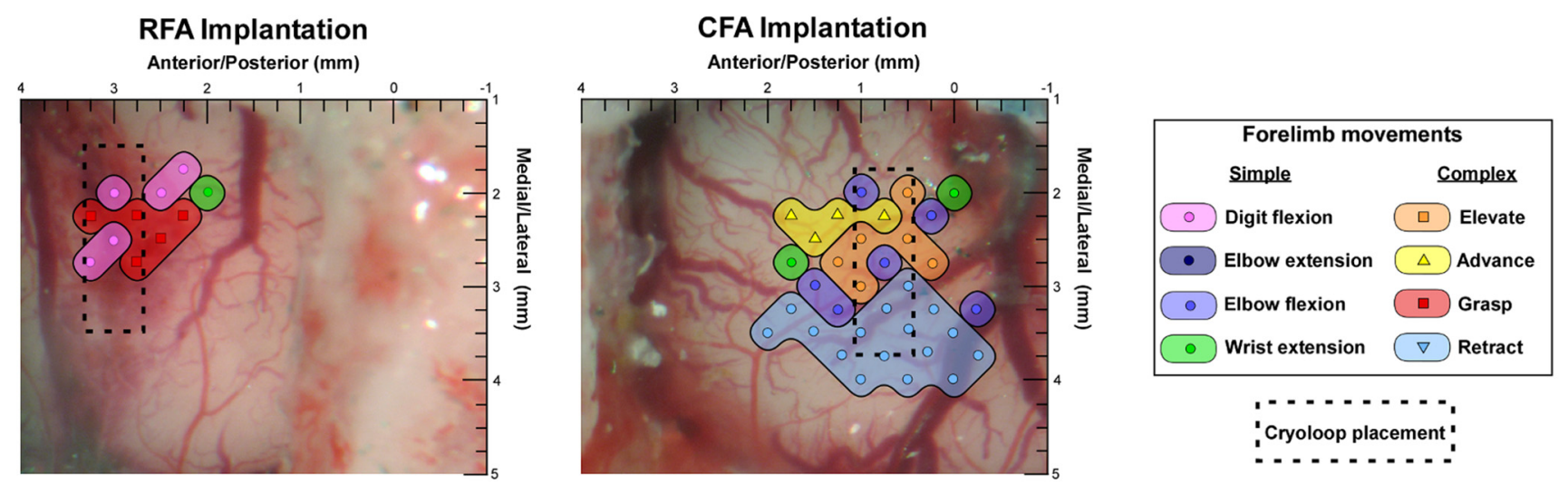

Figure 10. Representative forelimb movement representations derived following CFA and RFA cryoloop implantation groups. Long-duration ICMS was used to confirm cortical map integrity following cryoloop implantation and behavioral testing. No differences in the size of either the RFA ( $p=0.37)$ or CFA $(p=0.32)$ was observed between implanted and unimplanted groups.

vation isotherm boundaries (Fig. 10). No differences were observed in the size of either the RFA $\left(1.0 \pm 0.1\right.$ and $0.8 \pm 0.1 \mathrm{~mm}^{2}$, respectively; $p=0.37)$ or CFA $\left(4.3 \pm 0.2\right.$ and $3.9 \pm 0.2 \mathrm{~mm}^{2}$, respectively; $p=0.32$ ) between unimplanted and cryoloopimplanted groups.

\section{Discussion}

To investigate the functional contribution of complex movement representations in the behaving rat, we provide the first report of selective, acute, and reversible forelimb-grasping deficits during cortical cooling deactivation of forelimb grasping in neurologically intact rats. Our results provide further corroborative support for previous studies indicating a movement rather than muscle encoding functional network organization of motor cortex output revealed by LD-ICMS. Microstimulation studies have implicated two possible interpretations for the functional organization of motor cortex. A somatotopic mapping of body musculature is revealed using SD-ICMS ( $<50 \mathrm{~ms}$; Asanuma and Rosén, 1972; Andersen et al., 1975; Donoghue et al., 1992); whereas, complex, multijoint, movements are evoked with LDICMS on a behaviorally relevant time scale ( $\sim 500 \mathrm{~ms}$; Graziano et al., 2002, 2005; Haiss and Schwarz, 2005; Gharbawie et al., 2011b). We document a specialization and segregation of complex movement representations eliciting grasping movement in the RFA and reaching movement (forelimb elevate, advance, and retract) in the CFA in the rat under LD-ICMS, indicating a functional dissociation between the two motor areas that is not observed under SD-ICMS.

Four distinct complex forelimb movement representations were noted, driving the forelimb toward different postures comprising forelimb elevation, advancement, grasping, and retraction. Complex movements were found to exhibit marked topography with spatial segregation. Grasps were exclusively elicited within the RFA (Neafsey and Sievert, 1982), advances were observed within the rostromedial aspect of the CFA, retractions were localized to the caudolateral aspect of the CFA, and elevations were found predominantly in the caudomedial region of the CFA. Forelimb movements were evoked with short latency following stimulus onset, were held for the duration of the stimulation train, and were similar to those previously reported in other rat strains (Ramanathan et al., 2006; Bonazzi et al., 2013).

The functional role of observed complex movement representations suggested by microstimulation was then assessed in the behaving rat by use of chronically implanted subdural cortical cryoloops (Lomber et al., 1999), providing temporary and revers- ible functional deactivation of either the RFA or the CFA. We report for the first time a specific motor deficit resulting from the reversible deactivation of a complex movement representation in service of that behavior. Although cortical cooling deactivation of both forelimb motor areas was associated with significant deficits in single-pellet task success rates and attempts, a specific impairment in the grasping subcomponent of reaching (Whishaw et al., 2003) was observed solely during RFA deactivation, silencing grasping movement representations. Partial CFA deactivation, on the other hand, was associated with trends for increased impairments of elbow adduction toward the midline and reach advance. Cortical cooling of the RFA was also associated with a significant specific deficit in the vermicelli-handling test exhibited by a reduced ratio of contralateral forelimb manipulations that was not demonstrated during cooling of the CFA. These deficits were fully reversible when assessed following passive cortical rewarming to baseline temperatures.

At the temperatures used in this study, cooling results in a synaptic $\left(<20^{\circ} \mathrm{C}\right.$; Lomber et al., 1999$)$ but not a conduction $\left(<0^{\circ} \mathrm{C}\right.$; Bénita and Condé, 1972) block localized to within $1 \mathrm{~mm}$ of the loop. ICMS has been shown to elicit neuronal activation millimeters away from the stimulation site, even at low $(<10 \mu \mathrm{A})$ intensities, a finding ascribed to distal fiber activation (Histed et al., 2009). Movement representations derived via ICMS may then slightly under-represent underlying somatic activation. As the cortical deactivation area used in this experiment was selected to silence the much smaller RFA, it is possible that an incomplete inactivation of the CFA was achieved in some rats. Nonetheless, a significant deficit in reaching success was observed during CFA cooling. Adaptation of cooling deactivation for chronic use in rats was well tolerated, with intact movement representations probed with ICMS following behavioral assessment. Importantly, no differences in either reaching performance before and after cryoloop implantations, or the size of RFA and CFA between unimplanted and implanted rats were observed, indicating that the cryoloop implantation procedure itself was not related to the behavioral deficits noted during cooling deactivation. Effective deactivation was confirmed by the abolishment of ICMS responses during acute cooling, indicating similar isotherm deactivation thresholds, as reported in cats (Lomber et al., 1999) guinea pigs (Coomber et al., 2011), and rats (Antunes and Malmiera, 2011).

The topography of complex movement representations observed presently with a segregation of forelimb grasping (RFA) 
from forelimb reaching (CFA) lends support to an intriguing theory on the differential evolutionary origins for grasp and reach behavior in mammals. Dual visuomotor channel theory (Jeannerod, 1981) proposes that separate neural circuitry mediating forelimb reaching and grasping evolved simultaneously in the primate lineage from a demand to locomote and feed in an arboreal environment, and are unified under visual control for coordinated movement. Karl and Whishaw (2013) have recently proposed that forelimb reach abilities, predating primates, were instead derived independently with reaching exapted from the stepping movements of locomotion (limb elevation, advance, retract), and grasping exapted from food-handling behavior. Although the RFA and CFA exhibit a repeating fractured somatotopy of forelimb representation under SD-ICMS, a functional dissociation between the two motor areas is revealed under LD-ICMS, with grasping elicited from RFA and forelimbreaching movements bearing similarity to stepping patterns elicited from the CFA (elevation, advancement, and retraction). These two forelimb motor areas may then be homologous to the independent circuitry for grasping and reaching observed in primates (Gharbawie et al., 2011a,b; Kaas et al., 2011) and cats (for review, see Alstermark and Isa, 2012), and serve distinct functional, rather than hierarchical (Rouiller et al., 1993), roles in motor control. A functional distinction between separate distal (grasp) and proximal (arm) cortical circuitry has also been documented in primates where selective deficits in visuomotor grasping were produced with pharmacological inactivation of ventral premotor area F5 (Fogassi et al., 2001). Furthermore, reversible chemical inhibition of a complex defensive facial movement area in primates has been shown to result in a specific deficit in the same movement, without affecting musculature required for the task, while chemical disinhibition of the same regions results in the particular behavior being more likely to occur (Cooke and Graziano, 2004).

It is worthy to note that orofacial representations are found to border the RFA/grasp region laterally (Neafsey and Sievert, 1986), suggesting that the topographic distribution of adjacent complex movement representations organized for behavioral function (i.e., food handling and eating) extends even to disparate body parts. Following skilled motor learning in the singlepellet task, we observe a selective increase in corticobulbar representation overlap within forelimb motor areas under LD-ICMS. Encroachment of jaw representations within the RFA/ grasp area and neck representations within the CFA/reach area may indicate an experience-dependent, selective strengthening of feeding and pellet retrieval behaviors as this was not observed in untrained controls using identical stimulation parameters. Although network activation and recruitment properties from microstimulation are not fully understood, distinct complex movement representations have been shown to involve segregated corticofugal projections (Harrison et al., 2012). This is perhaps surprising noting that, while proximal and distal forelimb musculature in the rat is separately innervated by $\mathrm{C} 4$ and $\mathrm{C} 8$ spinal segments, respectively (McKenna et al., 2000), they are intermixed at the cellular level in the cortex (Wang et al., 2011). A functional parcellation of complex movement representations into distinct zones within forelimb motor areas, then, presumably results from differences in intrinsic intracortical circuitry as well as afferent and efferent projection pathways (Li et al., 1990; Rouiller et al., 1993; Haiss and Schwarz, 2005; Harrison et al., 2012).

The RFA has traditionally been believed to be homologous to the primate premotor cortex, with the CFA serves a capacity similar to the primate primary motor cortex (Neafsey and Sievert,
1982; Rouiller et al., 1993). Both areas, however, are known to contain direct corticospinal projections to the cervical enlargement (Wise et al., 1979). The notion of cortical motor hierarchy has been challenged by LD-ICMS with distinct complex movement representations found throughout premotor and primary motor areas in primates, emphasizing multiple, functionally distinct parallel streams of corticofugal projections (Graziano and Aflalo, 2007). It is of interest to note anecdotal reports of grasping deficits observed following lesions of the RFA in the initial report of its discovery (Neafsey and Sievert, 1982). In light of the functional and topographical dissociation of the grasping and reaching (elevate, advance, retract) movement representations observed presently, we suggest adopting new terminology of grasping area for the RFA and reaching area for the CFA. This would emphasize both their distinct behavioral roles and homology in the separation of grasping and reaching circuitry in primates.

\section{References}

Allred RP, Adkins DL, Woodlee MT, Husbands LC, Maldonado MA, Kane JR, Schallert T, Jones TA (2008) The vermicelli handling test: a simple quantitative measure of dexterous forelimb function in rats. J Neurosci Methods 170:229-244. CrossRef Medline

Alstermark B, Isa T (2012) Circuits for skilled reaching and grasping. Annu Rev Neurosci 35:559-578. CrossRef Medline

Andersen P, Hagan PJ, Phillips CG, Powell TP (1975) Mapping by microstimulation of overlapping projections from area 4 to motor units of the baboon's hand. Proc R Soc Lond B Biol Sci 188:31-36. CrossRef Medline

Antunes FM, Malmiera MS (2011) Effect of auditory cortex deactivation on stimulus-specific adaptation in the medial geniculate body. J Neurosci 31:17306-17316. CrossRef Medline

Asanuma H, Rosén I (1972) Topographical organization of cortical efferent zones projecting to distal forelimb muscles in the monkey. Exp Brain Res 14:243-256. CrossRef Medline

Bénita M, Condé H (1972) Effects of local cooling upon conduction and synaptic transmission. Brain Res 36:133-151. CrossRef Medline

Bonazzi L, Viaro R, Lodi E, Canto R, Bonifazzi C, Franchi G (2013) Complex movement topography and extrinsic space representation in the rat forelimb motor cortex as defined by long-duration intracortical microstimulation. J Neurosci 33:2097-2107. CrossRef Medline

Cooke DF, Graziano MS (2004) Super-flinchers and nerves of steel: defensive movements altered by chemical manipulation of a cortical motor area. Neuron 43:585-593. CrossRef Medline

Coomber B, Edwards D, Jones SJ, Shackleton TM, Goldschmidt J, Wallace MN, Palmer AR (2011) Cortical inactivation by cooling in small animals. Front Syst Neurosci 5:53. CrossRef Medline

Donoghue JP, Wise SP (1982) The motor cortex of the rat: cytoarchitecture and microstimulation mapping. J Comp Neurol 212:76-88. CrossRef Medline

Donoghue JP, Leibovic S, Sanes JN (1992) Organization of the forelimb area in squirrel monkey motor cortex: representation of digit, wrist, and elbow muscles. Exp Brain Res 89:1-19. Medline

Ferrier D (1874) Experiments on the brain of monkeys: No. 1. Proc Soc Lond 23:409-430.

Fogassi L, Gallese V, Buccino G, Craighero L, Fadiga L, Rizzolatti G (2001) Cortical mechanism for the visual guidance of hand grasping movements in the monkey-a reversible inactivation study. Brain 124:571-586. CrossRef Medline

Fritsche G, Hitzig E (1870) Electric excitability of the excitability of the cerebrum (Uber die elektrische Erregbarkeit des Grosshirns). Epilepsy Behav 15:123-130.

Gharbawie OA, Stepniewska I, Qi H, Kaas JH (2011a) Multiple parietalfrontal pathways mediate grasping in macaque monkeys. J Neurosci 31: 11660-11677. CrossRef Medline

Gharbawie OA, Stepniewska I, Kaas JH (2011b) Cortical connections of functional zones in posterior parietal cortex and frontal cortex motor regions in new world monkeys. Cereb Cortex 21:1981-2002. CrossRef Medline

Graziano MS, Aflalo TN (2007) Mapping behavioral repertoire onto the cortex. Neuron 56:239-251. CrossRef Medline

Graziano MS, Aflalo TN, Cooke DF (2005) Arm movements evoked by elec- 
trical stimulation in the motor cortex of monkeys. J Neurophysiol 94: 4209-4223. CrossRef Medline

Graziano MS, Taylor CS, Moore T (2002) Complex movements evoked by microstimulation of precentral cortex. Neuron 34:841-851. CrossRef Medline

Haiss F, Schwarz C (2005) Spatial segregation of different modes of movement control in the whisker representation of rat primary motor cortex. J Neurosci 25:1579-1587. CrossRef Medline

Harrison TC, Ayling OG, Murphy TH (2012) Distinct cortical circuit mechanisms for complex forelimb movement and motor map topography. Neuron 74:397-409. CrossRef Medline

Histed MH, Bonin V, Reid RC (2009) Direct activation of sparse, distributed populations of cortical neurons by electrical microstimulation. Neuron 63:508-522. CrossRef Medline

Jeannerod M (1981) Intersegmental coordination during reaching at natural visual objects. In Attention and performance IX (Long J, Badeley A, eds), pp 1530-169. Hillsdale, NJ: Erlbaum.

Kaas JH, Gharbawie OA, Stepniewska I (2011) The organization and evolution of dorsal stream multisensory motor pathways in primates. Front Neuroanat 5:34. CrossRef Medline

Karl JM, Whishaw IQ (2013) Different evolutionary origins for the reach and the grasp: an 1 explanation for dual visuomotor channels in primate parietofrontal cortex. Front Neurol 4:208. CrossRef Medline

Kleim JA, Barbay S, Nudo RJ (1998) Functional reorganization of the rat motor cortex following motor skill learning. J Neurophysiol 80:33213325. Medline

Lamoreux LW (1996) Coping with soft tissue movement in human motion analysis. In Human motion analysis: current applications and future directions (Harris GF, Smith PA, eds), pp 43-67. New York: IEEE.

Li XG, Florence SL, Kass JH (1990) Areal distribution of cortical neurons projecting to different levels of the caudal brain stem and spinal cord in rats. Somatosens Mot Res 7:315-335. Medline

Lomber SG, Payne BR (1996) Removal of two halves restores the whole: reversal of visual hemineglect during bilateral cortical or collicular inactivation in the cat. Vis Neurosci 13:1143-1156. CrossRef Medline

Lomber SG, Payne BR, Horel JA (1999) The cryoloop: an adaptable reversible cooling deactivation method for behavioral or electrophysiological assessment of neural function. J Neurosci Methods 86:179-194. CrossRef Medline

Luppino G, Matelli M, Camarda RM, Gallese V, Rizzolatti G (1991) Multiple representations of body movements in mesial area 6 and the adjacent cingulate cortex: an intracortical microstimulation study in the macaque monkey. J Comp Neurol 311:463-482. CrossRef Medline

McKenna JE, Prusky GT, Whishaw IQ (2000) Cervical motoneuron topography reflects the proximodistal organization of muscles and movements of the rat forelimb: a retrograde carbocyanine dye analysis. J Comp Neurol 419:286-296. CrossRef Medline

Neafsey EJ, Sievert C (1982) A second forelimb motor area exists in the rat frontal cortex. Brain Res 232:151-156. CrossRef Medline

Neafsey EJ, Bold EL, Haas G, Hurley-Gius KM, Quirk G, Sievert CF, Terreberry RR (1986) The organization of the rat motor cortex: a microstimulation mapping study. Brain Res 396:77-96. CrossRef Medline

Nudo RJ, Jenkins WM, Merzenich MM (1990) Repetitive microstimulation alters the cortical representation of movements in adult rats. Somatosens Mot Res 7:463-483. CrossRef Medline

Overduin SA, d'Avella A, Carmena JM, Bizzi E (2012) Microstimulation activates a handful of muscle synergies. Neuron 76:1071-1077. CrossRef Medline

Penfield W, Bouldrey E (1937) Somatic motor and sensory representation in the cerebral cortex of man as studied by electrical stimulation. Brain 60:389-443. CrossRef

Ramanathan D, Conner JM, Tuszynski MH (2006) A form of motor cortical plasticity that correlates with recovery of function after brain injury. Proc Natl Acad Sci U S A 103:11370-11375. CrossRef Medline

Rouiller EM, Moret V, Liang F (1993) Comparison of the connectional properties of the two forelimb areas of the rat sensorimotor cortex: support for the presence of a premotor or supplementary motor cortical area. Somatosens Mot Res 10:269-289. CrossRef Medline

Russell WMS, Burch RL (1959) The principles of humane experimental technique. London: Methuen.

Schieber MH (2001) Constraints on somatotopic organization in the primary motor cortex. J Neurophysiol 86:2125-2143. Medline

Tennant KA, Adkins DL, Scalco MD, Donlan NA, Asay AL, Thomas N, Kleim JA, Jones TA (2012) Skill learning induced plasticity of motor cortical representations is time and age-dependent. Neurobiol Learn Mem 98: 291-302. CrossRef Medline

Teskey GC, Monfils MH, VandenBerg PM, Kleim JA (2002) Motor map expansion following repeated cortical and limbic seizures is related to synaptic potentiation. Cereb Cortex 12:98-105. CrossRef Medline

Wang L, Conner JM, Rickert J, Tuszynski MH (2011) Structural plasticity within highly specific neuronal populations identifies a unique parcellation of motor learning in the adult brain. Proc Natl Acad Sci U S A 108: 2545-2550. CrossRef Medline

Whishaw IQ, Gorny B, Foroud A, Kleim JA (2003) Long-Evans and Sprague Dawley rats have similar skilled reaching success and limb representations in motor cortex but different movements: some cautionary insights into the selection of rat strains for neurobiological motor research. Behav Brain Res 145:221-232. CrossRef Medline

Wise SP, Murray EA, Coulter JD (1979) Somatotopic organization of corticospinal and corticotrigeminal neurons in the rat. Neuroscience 4:65-78. CrossRef Medline

Woolsey CN, Settlage PH, Meyer DR, Sencer W, Pinto Hamuy T, Travis AM (1952) Patterns of localization in precentral and "supplementary" motor areas and their relation to the concept of a premotor area. Res Publ Assoc Res Nerv Ment Dis 30:238-264. Medline

Yang XF, Kennedy BR, Lomber SG, Schmidt RE, Rothman SM (2006) Cooling produces minimal neuropathology in neocortex and hippocampus. Neurobiol Dis 23:637-643. CrossRef Medline

Yao D, Lavigne GJ, Lee JC, Adachi K, Sessle BJ (2013) Jaw-opening reflex and corticobulbar motor excitability changes during quiet sleep in nonhuman primates. Sleep 36:269-280. CrossRef Medline

Young NA, Vuong J, Flynn C, Teskey GC (2011) Optimal parameters for microstimulation derived forelimb movement thresholds and motor maps in rats and mice. J Neurosci Methods 196:60-69. CrossRef Medline 